\title{
Studi Morfometrik pada Os Scapula Hewan Kelinci New Zealand White (Oryctolagus cuniculus)
}

\author{
(GROSS AND MORPHOMETRICAL STUDIES ON SCAPULA OF NEW ZEALAND \\ WHITE RABBIT (Oryctolagus cuniculus))
}

\author{
Erwan Budi Hartadi ${ }^{1 *}$, Winda Kusuma Dewi ${ }^{1}$, Nadiya Listyasari ${ }^{1}$, Muhammad \\ Thohawi Elziyad Purnama ${ }^{2}$ \\ ${ }^{1}$ Bachelor of Veterinary Medicine, \\ ${ }^{2}$ Department of Veterinary Anatomy, \\ Faculty of Veterinary Medicine, Universitas Airlangga, \\ UNAIR C-Campus Mulyorejo, Surabaya, Jawa Timur, Indonesia, 60115 \\ Telp. (031)5993016, Fax. (031)5993015 \\ *Corresponding author: erwan.budi.hartadi-2015@fkh.unair.ac.id
}

\begin{abstract}
Abstrak
Penelitian ini bertujuan untuk melihat makroanatomi dan pengukuran morfometrik Os scapula dexter et sinister hewan kelinci New Zealand White. Os scapula hewan ini memiliki tiga tepi dan berbentuk segitiga. Permukaan bagian medial terdapat Fossa subscapularis yang terlihat paling legok. Permukaan lateral terdapat bagian yang menonjol yaitu Spina scapula. Spina ini membagi Fossa supraspinatus yang memiliki luas lebih kecil dibandingkan dengan Fossa infraspinatus yang jauh lebih lebar. Batas tepi caudal Os scapula merupakan yang paling tebal dibandingkan dengan kedua batas tepi lainnya. Tepi dorsal atau vertebral sedikit berbelok menuju ujung cranial. Sudut ventral Os scapula terdapat Cavitas glenoidales yang seperti cangkir dan melingkar dalam garis besar. Tuberculum supraglenoidales terlihat berkembang pada hewan ini. Tedapat Processus coracoideus yang berkembang seperti paruh. Indeks scapula (Scapular Index) pada hewan ini yaitu sebesar 50 pada sisi dexter dan 53,73 pada sisi sinister. Rasio lebar antara Fossa supraspinatus dan Fossa infraspinatus pada Os scapula dexter et sinister berturut-turut adalah 1:2,05 dan 1:2,04.
\end{abstract}

Kata kunci: kelinci New Zealand White, Os scapula, Cavitas glenoidales, Processus acromion, morfometrik

\begin{abstract}
The present study has been conducted on right and left Os scapulae of New Zealand White rabbit. Os scapulae was triangular in outline. Medial surface presented deeper Fossa subscapularis. The lateral surface was divided by a prominent Spina scapulae into a smaller Fossa supraspinatus and a much larger Fossa infraspinatus. The caudal border was the thickest of all the borders. Dorsal / vertebral border was notched towards cranial end. The ventral angle presented the Cavitas glenoidales which was cup-like and circular in outline. Tuberculum supra-glenoidales was small and Processus coracoideus was well defined and projected as beak-like process. The scapular index (SI) was 50 and 53,73 for right and left Os scapulae, respectively. The ratio of Fossa supraspinatus to Fossa infraspinatus was 1:2,05 and 1:2,04 for right and left Os scapulae respectively.
\end{abstract}

Key words: New Zealand White rabbit, Os scapulae, Cavitas glenoidales, Processus acromion, morphometrical

\section{PENDAHULUAN}

Kelinci jenis New Zealand White (Oryctolagus cuniculus) merupakan kelinci yang sering dipakai sebagai kelinci pedaging dan hewan laboratoris (Curnin and Bessert, 1985). Kelinci jenis ini memiliki rata-rata berat badan antara 8 sampai 12 pon. Ciri-ciri dari kelinci
New Zealand yaitu berwarna putih, dan terkadang berwarna merah hingga hitam. Memiliki telinga berukuran sedang, panjang dan tegak (Santoso and Sutarno, 2010).

Tulang kelinci lebih rapuh jika dibandingkan dengan mamalia lain, karena hanya 7-8 \% dari total massa tubuh. Kelinci mudah patah tulang atau retak pada saat proses handling dan restrain. 
Kandang kelinci seharusnya dibuat senyaman mungkin untuk tumbuh kembang tulang dan otot pada masa pertumbuhan, atau saat setelah terjadi cedera (Hayes et al., 2003).

Kelinci New Zealand White memiliki karakteristik bulu yang berwarna putih bersih, mata berwarna merah, telinga berwarna merah muda. Bobot saat anak umur 58 hari sekitar 1,8 $\mathrm{kg}$, bobot umur 4 bulan mencapai $2-3 \mathrm{~kg}$, bobot dewasa rata-rata $3,6 \mathrm{~kg}$, dan setelah lebih tua bobot maksimalnya mencapai 4,5-5 kg (Marhaeniyanto dkk., 2015).

Jenis New Zealand White merupakan kelinci albino, mempunyai rambut yang tidak berpigmen. Rambut kelinci ini berwarna putih, padat, tebal, halus dan memiliki mata berwarna merah. Kelinci ini berasal dari negara New Zealand, sehingga disebut New Zealand White. Keunggulan dari kelinci tersebut adalah pertumbuhannya yang cepat. Dengan pertumbuhan yang cepat tersebut, tulang sebagai penyokong tubuh tidak sekuat mamalia lain karena proses ossifikasi yang cepat. Tulang kelinci terutama pada bagian ekstremitas lebih mudah patah atau retak. Banyak kasus yang menyebutkan bahwa kelinci sering patah tulang jika beraktivitas tinggi atau mendapat perlakuan yang kasar (Hustamin, 2006).

Berdasarkan latar belakang diatas maka perlu dilakukan studi morfometrik dan gambaran secara makroanatomis dari Os scapula kelinci New Zealand White, kemudian dibandingkan dengan beberapa hewan yang memiliki rumpun sama seperti kelinci. Studi morfometrik Os scapula dilakukan menggunakan jangka sorong (Vernier caliper) berskala sentimeter $(\mathrm{cm})$.

\section{METODE PENELITIAN}

Penelitian ini dilakukan pada Os scapula kelinci New Zealand White jantan dewasa. Tulang diproses sesuai dengan teknik standar (Reghavan, 1964) dan selanjutnya dipelajari untuk mencatat morfologi secara makroanatomis. Parameter pengukuran menggunkan penggaris dan jangka sorong (Vernier calipers), adalah sebagai berikut:

Tabel 1. Parameter pengukuran (Sarma et al., 2017)

\begin{tabular}{cll}
\hline No & \multicolumn{1}{c}{ Parameter } & \multicolumn{1}{c}{ Keterangan } \\
\hline 1 & Panjang maksimum & Sepanjang Spina scapula \\
2 & Panjang diagonal & Dari Processus coracoid ke sudut caudal Os scapula \\
3 & Lebar Os scapula & Pada tiga tingkat yaitu dorsal, medial dan distal \\
4 & Panjang Spina scapula & Panjang spina yang berada di bagian lateral \\
5 & Tebal Os scapula & Pada tiga bagian yaitu dorsal, medial dan bagian proacromion \\
6 & Panjang acromion & Panjang penjuluran bagian distal setelah Spina scapula \\
7 & Panjang metacromion & Panjang penjuluran bagian distal setelah Acromion \\
8 & Keliling Cavitas & Lingkar mangkuk bagian distal sebagai persendian dengan Os \\
& glenoidales & humerus \\
9 & Antero-posterior diameter & Diameter dari depan ke belakang pada Cavitas glenoidales \\
& Cavitas glenoidales & \\
10 & Diameter transversal & Diameter diukur secara transversal pada Cavitas glenoidales \\
& Cavitas glenoidales & \\
11 & Indeks Scapula (SI) & Dihitung sebagai rasio antara panjang maksimum dan lebar \\
& & maksimum Os scapula. \\
12 & Lebar maksimum Fossa & Lebar maksimum Fossa supraspinatus (legokan diatas Spina \\
& supraspinatus & scapula) \\
13 & Lebar maksimum Fossa & Lebar maksimum Fossa Infraspinatus (legokan dibawah Spina \\
& infraspinatus & scapula) \\
14 & Rasio dari lebar maksimum & Perbandingan lebar maksimum Fossa supraspinatus dan Fossa \\
& Fossa supraspinatus dan & infraspinatus \\
& Fossa infraspinatus &
\end{tabular}




\section{HASIL DAN PEMBAHASAN}

Os scapula memiliki bentuk datar, pipih dan terlihat triangular dari sisi luar (Gambar 1). Bentuk ini hampir mirip dengan ruminansia (Getty, 1975), namun dengan versi yang lebih

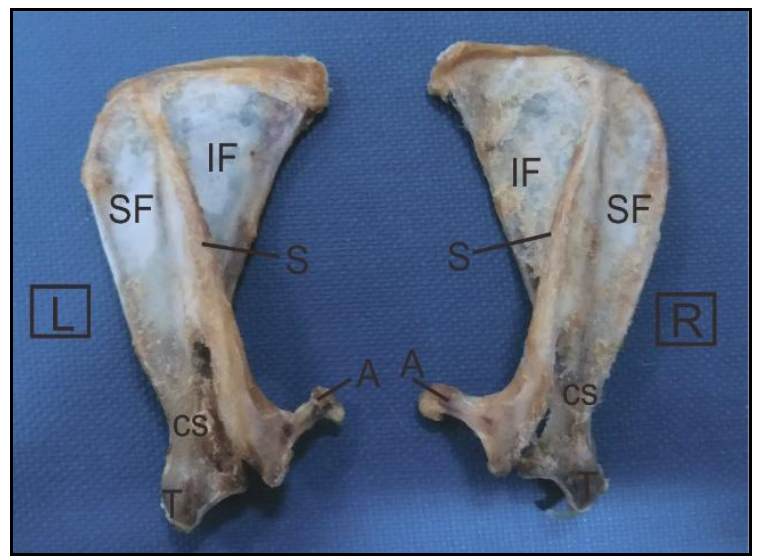

Gambar 1. Os scapula tampak lateral sisi dexter (R) dan sinister (L), Fossa supraspinatus (SF), Fossa infraspinatus (IF), Tuber spina scapula (S), Processus acromion (A), Tuberculum supraglenoidales (T) dan Collumna scapula (CS).

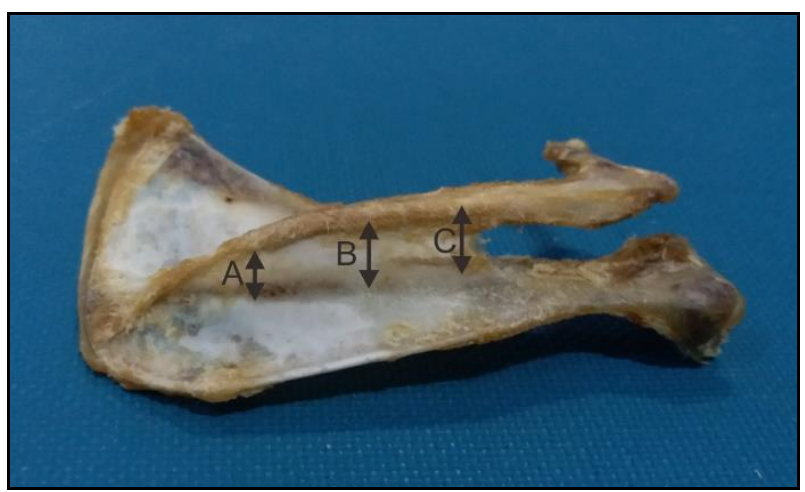

Gambar 3. Lateral dari Os scapula yang memperlihatkan lebar Spina scapula. Terbagi dalam tiga bagian yaitu dorsal (A), medial (B) dan distal (C).

Sisi medial dari Os scapula terdapat Fossa subscapularis, seperti pada hewan ruminansia (Getty, 1975). Fossa ini berkembang disepanjang Spina scapula. Berbeda dengan ruminansia yang kecil. Tulang pada hewan ini memiliki ukuran lebih besar jika dibandingkan dengan tikus dan marmut (Popesko et al., 1992). Os scapula pada hewan kelinci memiliki dua sisi, tiga sudut dan tiga tepi.

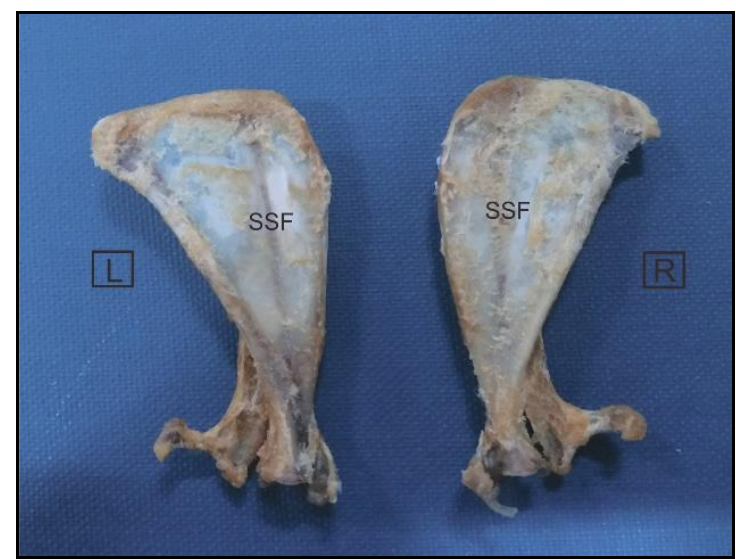

Gambar 2. Os scapula tampak medial sisi dexter (R) dan sinister (L). Terdapat legokan di daerah medial, yaitu Fossa subscapularis (SSF).

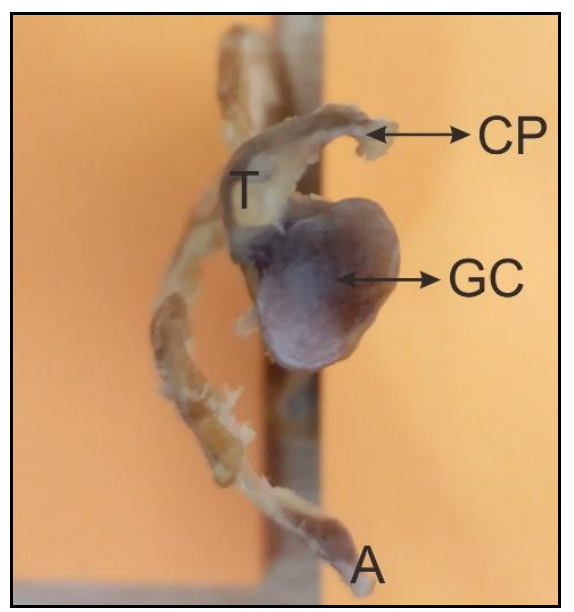

Gambar 4. Sudut ventral dari Os scapula yang memperlihatkan Processus acromion (A), Tuberculum supra-glenoidales (T), Cavitas glenoidales (GC) dan Processus coracoideus (CP).

berkembang tertumpu pada bagian tengah (Popesko et al., 1992).

Sisi lateral dari Os scapula terdapat bagian yang menonjol yaitu Spina scapula dan Acromion yang sangat berkembang. Sedikit 
berbeda dengan Acromion ruminansia (Getty, 1975) yang lebih pendek jika dilakukan skala perbandingan. Spina scapula membagi kedua fossa, yaitu Fossa supraspinatus dan Fossa infraspinatus. Fosa supraspinatus telihat lebih sempit jika dibandingkan dengan Fossa infraspinatus.

Tabel 2. Biometri Os scapula kelinci New Zealand White

\begin{tabular}{clcc}
\hline No & \multicolumn{1}{c}{ Parameter } & Os scapula dexter & Os scapula sinister \\
\hline 1 & Panjang maksimum & $6,6 \mathrm{~cm}$ & $6,7 \mathrm{~cm}$ \\
2 & Panjang diagonal & $6,9 \mathrm{~cm}$ & $7 \mathrm{~cm}$ \\
3 & Lebar Os scapula & & \\
& a. Dorsal & $3,27 \mathrm{~cm}$ & $3,30 \mathrm{~cm}$ \\
& b. Medial & $1,76 \mathrm{~cm}$ & $1,82 \mathrm{~cm}$ \\
& c. Distal & $1,06 \mathrm{~cm}$ & $1,10 \mathrm{~cm}$ \\
4 & Panjang Spina scapula & $5,83 \mathrm{~cm}$ & $5,74 \mathrm{~cm}$ \\
5 & Tebal Os scapula & & \\
& $\quad$ a. Dorsal & $0,38 \mathrm{~cm}$ & $0,34 \mathrm{~cm}$ \\
& $\quad$ b. Medial & $0,25 \mathrm{~cm}$ & $0,20 \mathrm{~cm}$ \\
& $\quad$ c. Proacromion & $0,2 \mathrm{~cm}$ & $0,30 \mathrm{~cm}$ \\
6 & Panjang acromion & $1,80 \mathrm{~cm}$ & $1,72 \mathrm{~cm}$ \\
7 & Panjang metacromion & $2,38 \mathrm{~cm}$ & $2,2 \mathrm{~cm}$ \\
8 & Keliling Cavitas glenoidales & $2,67 \mathrm{~cm}$ & $2,61 \mathrm{~cm}$ \\
9 & Antero-posterior diameter Cavitas & $1,2 \mathrm{~cm}$ & $1,3 \mathrm{~cm}$ \\
& glenoidales & & \\
10 & Diameter transversal Cavitas glenoidales & $0,75 \mathrm{~cm}$ & $0,77 \mathrm{~cm}$ \\
11 & Indeks Scapula (SI) & 50 & 53,73 \\
12 & Lebar maksimum Fossa supraspinatus & $1 \mathrm{~cm}$ & $1,08 \mathrm{~cm}$ \\
13 & Lebar maksimum Fossa infraspinatus & $2,05 \mathrm{~cm}$ & $2,2 \mathrm{~cm}$ \\
14 & Rasio dari lebar maksimum Fossa & $1: 2,05$ & $1: 2,04$ \\
& supraspinatus dan Fossa infraspinatus & & \\
\hline & & &
\end{tabular}

Spina scapula berkembang dengan baik dalam garis besar (Gambar 1). Spina ini memiliki panjang hingga Collumna scapula dan berakhir sebagai bagian runcing (Processus acromion). Di tengah Spina scapula terdapat perkembangan tulang seperti benjolan, yaitu Tuber spina scapula.

Processus acromion pada Os scapula kelinci sedikit berbeda dengan hewan lainnya. Processus ini berkembang menuju kearah caudal (Gambar 1). Berbeda dengan ruminansia yang berkembang lurus mengikuti alur dari Spina scapula (Getty, 1975). Pada tikus juga ditemukan Processus acromion yang lurus seperti pada ruminansia (Popesko et al., 1992). Masih belum diketahui fungsi yang pasti dari membeloknya Processus acromion kearah caudal sampai saat ini. Namun secara umum
Processus acromion berfungsi untuk membantu proses lokomosi atau pergerakan hewan dengan ekstremitas (Seckel and Janis, 2008).

Tiga tepi Os scapula yaitu bagian dorsal / vertebral, cranial dan caudal. Tepi caudal Os scapula terlihat paling tebal jika dibandingkan dengan kedua sisi lain seperti pada ruminansia (Getty, 1975). Tepi pada Os scapula kelinci ini hampir mirip dengan Os scapula tikus (Popesko et al., 1992).

Tepi dorsal atau vertebral Os scapula ini paling tebal, jika dibandingkan dengan tepi caudal dan tepi cranial. Tebal dari ketiga tepi tersebut relatif sama. Kedua sudut cranial dan caudal berkembang sangat baik. Sudut ventral terdapat Cavitas glenoidales yang berbentuk seperti mangkuk dan memiliki garis yang melingkar (Gambar 4). Cavitas glenoidales lebih 
dangkal dibandingkan dengan sapi. Processus coracoideus pada kelinci lebih berkembang jika dibandingkan dengan kuda (Raghavan, 1964).

Tuber spina scapula berkembang secara kompak mengikuti alur dari Spina scapula. Berbeda dengan kuda yang memiliki perkembangan Tuber spina scapula di daerah tengah (Raghavan, 1964). Pada sapi juga hanya berkembang pada bagian tengah Spina scapula (Getty, 1975). Tuber spina scapula kelinci melekuk kearah caudal.

Tuberculum supra glenoidales berkembang di area Cavitas glenoidales. Pada bagian ini terdapat taju yang berkembang baik, yaitu Processus coracoideus. Pada sapi Processus coracoideus kurang berkembang baik jika dibandingkan milik kelinci. Begitu juga pada kuda, yang memiliki Processus coracoideus, namun kurang berkembang (Getty, 1975).

Hasil dari biometrik pada Tabel 2 diatas, diambil dari Os scapula kelinci New Zealand White jantan. Pajang maksimal Os scapula diukur mengikuti Spina scapula (tanpa Cartilago scapularis) yaitu $6,6 \mathrm{~cm}$ pada sisi dexter dan 6,7 pada sisi sinister. Panjang diagonal Os scapula ini $6,9 \mathrm{~cm}$ pada sisi dexter dan $7 \mathrm{~cm}$ pada sisi sinister. Lebar tulang ini terbagi menjadi tiga bagian. Pada Os scapula dexter mendapatkan hasil lebar 3,27 cm bagian dorsal, $1,76 \mathrm{~cm}$ bagian medial dan $1,06 \mathrm{~cm}$ bagian distal. Persentase penurunan lebar Os scapula dari bagian dorsal ke medial yaitu sebesar 46,18\%, dari medial ke distal yaitu $39,77 \%$. Secara keseluruhan penurunan lebar Os scapula dexter dari bagian dorsal ke distal yaitu $67,58 \%$. Sisi sinister Os scapula bagian dorsal, medial dan distal berturut-turut memiliki lebar $3,30 \mathrm{~cm}, 1,82$ $\mathrm{cm}$ dan $1,10 \mathrm{~cm}$. Persentase penurunan lebar dari bagian dorsal ke medial yaitu 44,85\%, sedangkan dari bagian medial ke distal yaitu $39,56 \%$. Secara keseluruhan persentase penurunan lebar dari bagian dorsal ke distal yaitu $66,67 \%$.

Indeks scapula (Scapular Index) pada hewan kelinci New Zealand White yaitu 50 pada sisi dexter. Sisi sinister mendapatkan hasil indeks scapula 53,73. Berbeda jika dibandingkan dengan domba yaitu 65,83 dan kambing yaitu
43,63 (Dalvi et al., 1997). Pada rusa India memiliki indeks 54.36 pada sisi dexter dan 55.21 pada sisi sinister (Sasan et al., 2018).

Panjang Spina scapula yaitu $5,83 \mathrm{~cm}$ pada sisi dexter dan 5,74 pada sisi sinister. Tebal scapula terbagi menjadi tiga bagian, yaitu dorsal, medial dan proacromion. Sisi dexter berturutturut memperoleh hasil $0,38 \mathrm{~cm}, 0,25 \mathrm{~cm}$ dan $0,27 \mathrm{~cm}$. Sisi sinister memperoleh hasil yang hampir sama dengan sisi dexter, yaitu $0,34 \mathrm{~cm}$, $0,20 \mathrm{~cm}$ dan $0,30 \mathrm{~cm}$. Panjang acromion dan metacromion pada sisi dexter berturut-turut yaitu $1,80 \mathrm{~cm}$ dan $2,38 \mathrm{~cm}$. Sisi sinister memperoleh hasil pengukuran berturut-turut $1,72 \mathrm{~cm}$ dan 2,2 $\mathrm{cm}$. Terlihat lebih pendek sisi sinister dibandingkan dengan sisi dexter, namun tidak terlalu signifikan.

Keliling Cavitas glenoidales pada sisi dexter yaitu 2,67 cm, sedangkan pada sisi sinister 2,61 $\mathrm{cm}$. Antero-posterior diameter Cavitas glenoidales pada sisi dexter yaitu 1,2 cm dan 1,3 $\mathrm{cm}$ pada sisi sinister. Diameter transversal Cavitas glenoidales sisi dexter mendapatkan hasil $0,75 \mathrm{~cm}$ dan pada isi sinister $0,77 \mathrm{~cm}$. Hasil tersebut memiliki perbedaan yang tidak terlalu signifikan jika dibandingkan antara sisi dexter dan sinister.

Lebar maksimum Fossa supraspinatus sisi dexter yaitu $1 \mathrm{~cm}$ dan sisi sinister $1,08 \mathrm{~cm}$. Lebar maksimum Fossa infraspinatus sisi dexter yaitu 2,05 $\mathrm{cm}$ dan 2,2 $\mathrm{cm}$ pada isi sinister. Rasio dari lebar maksimum antara Fossa supraspinatus dan Fossa infraspinatus sisi dexter yaitu mendapatkan hasil $1: 2,05$. Rasio sisi sinister mendapatkan hasil $1: 2,04$. Dari rasio kedua $O s$ scapula ini memiliki perbedaan yang tidak signifikan.

\section{KESIMPULAN}

Scapula hewan kelinci New Zealand White hampir mirip seperti hewan ruminansia lain. Memiliki bentuk datar, pipih dan terdapat acromion yang berkembang baik. Tiga tepi pada tulang ini yaitu tepi dorsal atau vertebral, tepi cranial dan tepi caudal. Perbedaan yang paling mencolok dari Os scapula ini yaitu Processus acromion yang berkembang baik dan mengarah 
ke caudal. Fossa subscapularis pada bagian medial Os scapula berkembang sepanjang pertumbuhan Spina scapula pada bagian lateral. Rasio dari lebar maksimum Fossa supraspinatus dengan Fossa infraspinatus adalah 1 : 2,05 pada sisi dexter, sedangkan 1 : 2,04 pada sisi sinister. Indeks scapula (SI) pada kelinci New Zealand White yaitu 50 pada sisi dexter dan 53,73 pada sisi sinister.

\section{UCAPAN TERIMA KASIH}

Peneliti mengucapkan terima kasih kepada Departemen Anatomi Veteriner, Fakultas Kedokteran Hewan, Universitas Airlangga atas izin yang diberikan dan peminjaman tulang untuk dilakukan penelitian.

\section{DAFTAR PUSTAKA}

Curnin, D.M. Mc and J.M. Bessert. 1985. Clinical Textbook for Veterinary Technicians. Saunders. China.

Dalvi, R.S., V.R. Bhamburkar, O.N. Ladukar and S.B. Banubakode. 1997. Morphometric Study on Scapulae of Some Domestic and Wild Animals. Tech. Bul. XII Convention and National Symposium of IAVA. p44.

Getty, R. 1975. Sisson and Grossman's The Anatomy of the Domestic Animals Vol: I. 5th edition, W.B. Saunders Company. Philadelphia.

Getty, R. 1975. Sisson and Grossman's The Anatomy of the Domestic Animals Vol: II. 5th edition, W.B. Saunders Company. Philadelphia.

Hayes, R.A., B.J. Richardson, and S.G. Wyllie, 2003. To fix or not to fix: the role of 2phenoxyethanol in rabbit, Oryctolagus cuniculus, chin gland secretion. J Chem Ecol, 1051-1064.

Hustamin, R., 2006. Panduan Pemeliharaan Kelinci Hias. Agromedia Pustaka. Jakarta.

Marhaeniyanto, E., S. Rusmiwari, S. Susanti. 2015. Pemanfaatan daun kelor untuk meningkatkan produksi ternak kelinci New Zealand White. Buana Sains, 15(2): 119126.

Popesko, P., V. Ratjova, J. Horak. 1992. A Colour Atlas of Anatomy of Small Laboratory Animals Vol. II: Rat, Mouse, Hamster. Saunders Company. London.

Raghavan, D., 1964. Anatomy of ox. Indian Council of Agricultural Research, New Delhi. p97-117.

Santoso, U. dan Sutarno, 2010. Slaughter weight and carcass of male New Zealand White rabbit after rationing with koro bean (Mucuna pruriens var. utilis). Bioscience, 1(3): 117-122.

Sarma, K., J.S. Sasan and S. Suri, 2017. Gross and Morphometrical Studies on Scapula of Civet Cat (Viverricula indica). Int J Pure App Biosci, 5(6): 80-85.

Sasan, J.S., K. Sarma and S. Suri, 2018. Gross and Morphometrical Studies on Scapula of Barking Deer (Muntiacus muntjak). Int $J$ Curr Microbiol App Sci, 7(2): 2820-2825.

Seckel, L. and C. Janis, 2008. Convergences in scapula morphology among small cursorial mammals: an osteological correlate for locomotory specialization. J Mammal Evol, 15(4): 261. 